\title{
Diet, exercise, obesity, smoking and alcohol consumption in cancer survivors and the general population: a comparative study of 16282 individuals
}

\author{
Z Wang $^{1}$, P McLoone ${ }^{1}$ and D S Morrison ${ }^{*}, 1$ \\ ${ }^{1}$ West of Scotland Cancer Surveillance Unit, Institute of Health and Wellbeing, University of Glasgow, 1 Lilybank Gardens, \\ Glasgow, G12 8RZ, UK
}

Background: Cancer survivors may be particularly motivated to improve their health behaviours.

Methods: We compared health behaviours and obesity in cancer survivors with the general population, using household survey and cancer registry data.

Results: Cancer survivors were more likely than those with no history of cancer to eat fruit and vegetables $\left(\mathrm{OR}_{\mathrm{adj}} 1.41,95 \% \mathrm{Cl} 1.19-\right.$ 1.66), less likely to engage in physical activity $\left(\mathrm{OR}_{\text {adj }} 0.79,95 \% \mathrm{Cl} 0.67-0.93\right)$ and more likely to have stopped smoking $\left(\mathrm{OR}_{\mathrm{adj}} 1.25\right.$, $95 \% \mathrm{Cl} 1.09-1.44)$.

Conclusions: Most health-related behaviours were better in cancer survivors than the general population, but low physical activity levels may be amenable to health promotion interventions.

There may be opportunities to change the health behaviours of cancer survivors to reduce the risk of further malignancies, other preventable diseases and to improve cancer-related and overall survival. However, it is not known whether cancer survivors are likely to have better, similar, or worse health behaviours than the general population and therefore whether they should be targeted for health improvement interventions.

It might be expected that many cancer patients have healthrelated behaviours, which contributed to the development of their malignancy (Mayer et al, 2007; Mayer and Carlson, 2011). However, having been diagnosed with cancer, patients may be motivated to change their behaviour (Bassett et al, 2012). These effects are opposing and may explain why researchers have found few significant differences in health behaviours among cancer survivors compared with the general population (Courneya, 2003; Coups and Ostroff, 2005; Courneya et al, 2008; Rogers et al, 2008; Fairley et al, 2010).

It is thought that some changes in health behaviours may be spontaneously provoked by the diagnosis of cancer and interactions with health-care professionals, so called 'teachable moments' (Demark-Wahnefried et al, 2005, 2006). Research on whether changes in health behaviours do occur is limited and much of the work has focused on female breast cancer survivors (Alfano et al, 2009; Littman et al, 2010; Sprague et al, 2010).

To inform these issues we describe health behaviours (fruit and vegetable consumption, physical activity, smoking and alcohol consumption) and obesity in cancer survivors compared with people with no history of cancer and people who subsequently developed cancer.

\section{MATERIALS AND METHODS}

Data and health behaviour definitions. We obtained data from Scottish Health Surveys in 1995, 1998, 2003 and 2008. These are cross-sectional nationally representative general health surveys from Scotland, UK (population 5.2 million); details of these surveys 
are described elsewhere (Corbett et al, 2009). Approval was obtained from all participating Health Boards' ethics committees.

The surveys were linked to the national Scottish Cancer Registry to identify whether a participant had received a cancer diagnosis up to December 2008. Cancer was defined as all invasive malignancies (International Classification of Diseases, Revision 10, C00-C96). Individual cancer sites were defined as lung (ICD-10 C33-34), breast (C50), bowel (C18-20) and prostate (C61).

Behavioural and anthropometric risk factors were dichotomized so that they either did or did not satisfy the following criteria: $\geqslant 5$-a-day-combined consumption of fruit and vegetables equals 5 or more $80 \mathrm{~g}$ or $2.8 \mathrm{oz}$ portions per day; obese-nurse-measured body mass index $\geqslant 30 \mathrm{~kg} \mathrm{~m}^{-2} ; \geqslant 2 \mathrm{~h}$ physical activity/week-physical activity includes home-based activities, walking, sports and exercise, and activity at work; alcohol > recommended-weekly consumption exceeds 21 units for men and 14 units for women (1 unit $=10 \mathrm{ml}$ or $8 \mathrm{~g}$ or $0.35 \mathrm{fl} \mathrm{oz} \mathrm{ethanol);} \mathrm{former} \mathrm{smoker} \mathrm{and} \mathrm{former} \mathrm{drinker,} \mathrm{as} \mathrm{self-}$ reported at the time of survey.

An area-based measure of socio-economic deprivation, the Scottish Index of Multiple Deprivation (SIMD) was employed (Scottish Index of Multiple Deprivation: Background and Methodology. The Scottish Government, 2012). This uses seven domains (employment, income, health, education, access to services, crime and housing) to rank geographic areas, from which we used quintiles from 1 (most deprived) to 5 (least deprived).

Analysis and statistical methods. Exploratory descriptive analyses using $\chi^{2}$-tests, independent sample $t$-tests and binary logistic regressions were carried out. Adjusted, multivariable analyses with each dichotomous behaviour variable as the dependant variable and age, sex and SIMD as explanatory variables were carried out. All analyses were unweighted, conducted with STATA software, version 11 and the conventional threshold of $P<0.05$ used to indicate statistical significance.

We compared health behaviours in cancer patients who were diagnosed relatively recently ( $<2$ years), much earlier ( $\geqslant 2$ years) before the survey and soon after the survey ( $<2$ years) with those who were diagnosed two or more years after the survey.

\section{RESULTS}

The total sample size was 31136 respondents. We excluded 15077 respondents who were aged $<45$ years because the incidence of cancer is much less common at these ages. The final sample comprised 16282 participants among whom 922 (5.7\%) had a diagnosis of cancer before they were surveyed (cancer survivors) and 1257 (7.7\%) were diagnosed with cancer following the survey. All respondents had complete data for age and sex, and missing data comprised the following: 1628 for socio-economic data; 1 for smoking status; 10 for alcohol use; 10 for fruit and vegetable consumption; 4329 for physical activity and 2250 for BMI. Cancer survivors were significantly older than those with no history of cancer (mean ages 59.7 vs 66.6 years, respectively, $P<0.001$ ). There were no significant differences in proportions of females $(55.8 \%$ in both, $\left.\chi^{2}=0.002, P=0.96\right)$ or in socio-economic distributions $\left(\chi^{2}=5.30, P=0.26\right)$ between the two groups (Table 1$)$.

Cancer survivors, compared with those with no history of cancer, were significantly more likely to eat at least five portions of fruit and vegetables a day $\left(21 \%\right.$ vs $15 \%, \mathrm{OR}_{\text {adj }} 1.41,95 \%$ CI $1.19-$ $1.66)$, less likely to take at least $2 \mathrm{~h}$ physical activity a week (35\% vs $45 \%, \mathrm{OR}_{\text {adj }} 0.79,95 \%$ CI $0.67-0.93$ ) and more likely to have

\section{Table 1. Demographic and behavioural characteristics of Scottish Health Survey respondents, 1995, 1998, 2003, 2008}

\begin{tabular}{|c|c|c|c|c|}
\hline & & & \multicolumn{2}{|c|}{$\begin{array}{c}\text { Respondents without } \\
\text { a previous cancer } \\
n(\%)\end{array}$} \\
\hline & $\begin{array}{c}\text { All respondents } \\
n(\%)\end{array}$ & $\begin{array}{c}\text { Respondents with } \\
\text { a previous cancer } \\
n(\%)\end{array}$ & $\begin{array}{c}\text { Subsequent } \\
\text { cancer }\end{array}$ & $\begin{array}{c}\text { No subsequent } \\
\text { cancer }\end{array}$ \\
\hline \multicolumn{5}{|l|}{ Sex } \\
\hline $\begin{array}{l}\text { Men } \\
\text { Women }\end{array}$ & $\begin{array}{l}7200(44.2) \\
9082(55.8)\end{array}$ & $\begin{array}{l}407(44.1) \\
515(55.9)\end{array}$ & $\begin{array}{l}598(47.6) \\
659(52.4)\end{array}$ & $\begin{array}{l}6195(43.9) \\
7908(56.1)\end{array}$ \\
\hline Median age (IQR) & $59(52-67)$ & $67(59-74)^{a}$ & $62(56-69)$ & $58(51-66)$ \\
\hline \multicolumn{5}{|l|}{ SIMD } \\
\hline $\begin{array}{l}1 \text { (most deprived) } \\
2 \\
3 \\
4 \\
5 \text { (least deprived) }\end{array}$ & $\begin{array}{l}2863(19.5) \\
3125(21.3) \\
3136(21.4) \\
3050(20.8) \\
2480(16.9)\end{array}$ & $\begin{array}{r}170(18.4) \\
181(19.6) \\
191(20.7) \\
209(22.7) \\
171(18.5)\end{array}$ & $\begin{array}{l}284(22.7) \\
271(21.6) \\
285(22.8) \\
228(18.2) \\
184(14.7)\end{array}$ & $\begin{array}{l}2409(19.3) \\
2673(21.4) \\
2660(21.3) \\
2613(20.9) \\
2125(17.0)\end{array}$ \\
\hline \multicolumn{5}{|l|}{ Cancer } \\
\hline $\begin{array}{l}\text { All } \\
\text { Lung } \\
\text { Breast } \\
\text { Prostate } \\
\text { Bowel }\end{array}$ & $\begin{array}{l}2179(100) \\
251(11.5) \\
355(16.3) \\
171(7.8) \\
235(10.8)\end{array}$ & $\begin{aligned} 922 & (100) \\
39 & (4.2) \\
206 & (22.3) \\
71 & (7.7) \\
105 & (11.4)\end{aligned}$ & $\begin{array}{l}1257(100) \\
212(16.9) \\
149(11.9) \\
100(8.0) \\
130(10.3)\end{array}$ & $14103(0)$ \\
\hline \multicolumn{5}{|l|}{ Behaviour } \\
\hline $\begin{array}{l}\geqslant 5 \text {-a-day } \\
\geqslant 2 \mathrm{~h} \text { PA per week } \\
\text { Current smoker } \\
\text { Former smoker } \\
\text { Alcohol > recommended } \\
\text { Former drinker } \\
\text { Obesity }\end{array}$ & $\begin{array}{l}2552(15.7) \\
5315(32.6) \\
4512(27.7) \\
5464(33.6) \\
2980(18.3) \\
1079(6.6) \\
4020(24.7)\end{array}$ & $\begin{array}{l}193(20.9)^{\mathrm{a}} \\
248(26.9)^{\mathrm{a}} \\
197(21.4) \\
400(43.4)^{\mathrm{a}} \\
151(16.4) \\
79(8.6) \\
208(22.6)\end{array}$ & $\begin{array}{l}117(9.3) \\
284(22.6) \\
447(35.6) \\
421(33.5) \\
238(18.9) \\
74(5.9) \\
304(24.2)\end{array}$ & $\begin{array}{l}2242(15.9) \\
4783(33.9) \\
3868(27.4) \\
4643(32.9) \\
2591(18.4) \\
926(6.6) \\
3508(24.9)\end{array}$ \\
\hline
\end{tabular}


stopped smoking ( $43 \%$ vs 33\%, OR adj 1.25 , 95\% CI 1.09-1.44) compared with respondents with no history of cancer (Table 2). Within each major cancer site, breast cancer survivors were more likely to eat fruit and vegetables $\left(\mathrm{OR}_{\mathrm{adj}} 1.72,95 \% \mathrm{CI} 1.25-2.37\right)$ and to be former smokers $\left(\mathrm{OR}_{\text {adj }} 1.45,95 \% \mathrm{CI} 1.09-1.93\right)$ and lung cancer survivors were less likely to be obese $\left(\mathrm{OR}_{\mathrm{adj}} 0.32,0.11-0.92\right)$. No other significant site-specific associations were found.

Cancer survivors compared with future cancer patients-time since/to diagnosis. Fruit and vegetable consumption and being a former drinker were highest among cancer survivors who had been diagnosed $<2$ years before, but the effect was smaller than $\geqslant 2$ years after diagnosis (Table 3). Similarly, current smoking was least prevalent among those surveyed within 2 years of diagnosis and higher in those diagnosed $\geqslant 2$ years before. Being a former drinker was only significantly raised among those within 2 years of a cancer diagnosis. Within each cancer site, women with a more recent diagnosis of breast cancer were most likely to eat five or more portions of fruit and vegetables per day $\left(\mathrm{OR}_{\mathrm{adj}} 3.33, P=0.011\right.$ and $\mathrm{OR}_{\text {adj }} 2.55, P=0.008$ in those diagnosed $<2$ years and $>2$ years before survey, respectively); and those with a more recent diagnosis of colorectal cancer were more likely to report being former drinkers $\left(\mathrm{OR}_{\mathrm{adj}} 6.04, P=0.005\right.$ and $\mathrm{OR}_{\mathrm{adj}} 0.65, P=0.553$ in those diagnosed $<2$ years and $>2$ years before survey, respectively).

\section{DISCUSSION}

In this national survey of over 16000 adults, we found that cancer survivors ate more fruit and vegetables and were more likely to have stopped smoking, but took less physical activity compared with those who had not had cancer. Lower levels of physical activity among cancer survivors have been reported in the English Longitudinal Study of Ageing (Williams et al, 2013), while the NHANES study reported both longer durations of sedentary behaviour but also significantly higher moderate intensity and frequency of exercise (Kim et al, 2013). We found breast cancer survivors were more likely to eat fruit and vegetables, and to have stopped smoking, in contrast to the findings of a recent prospective Danish study (Bidstrup et al, 2013). Lung cancer survivors were more likely to have stopped smoking compared with those who would subsequently develop cancer. This may be a survivor bias or a true behavioural change (Evangelista et al, 2003). We found that recommended health behaviours were more prevalent among those who had been more recently diagnosed, but the effect size was smaller two or more years after the diagnosis.

The low levels of physical activity that we observed may be amenable to interventions. CanChange (Hawkes et al, 2013), the Copenhagen Physical Activity after Cancer Treatment trial (Midtgaard et al, 2013) and BeWEL (Anderson et al, 2014) have reported significant improvements in physical activity in similar patient populations, with CanChange and BeWEL also achieving reductions in BMI among overweight patients. Adherence to recommended preventative behaviours may improve quality of life (Inoue-Choi et al, 2013) and survival (Izano et al, 2013), although the association may be confounded by underlying systemic illness. A recent systematic review of randomized controlled trials of physical activity interventions among cancer survivors found evidence for a range of physiological, physical and psychological benefits but did not identify any papers that reported outcomes

Table 2. Health behaviours in cancer survivors and those with no previous cancer

\begin{tabular}{|l|c|c|c|c|c|c|c|}
\hline \multicolumn{7}{|c|}{} & \multicolumn{7}{|c|}{ Number (\%) by cancer history } \\
\hline Risk factor & No cancer & All survivors & Lung & Breast & bowel & prostate & All survivors \\
\hline & $N(\%)$ & $N(\%)$ & & & & \\
\hline$\geqslant 5$-a-day & $2359(15 \%)$ & $193(21 \%)$ & $1(3 \%)$ & $55(27 \%)$ & $23(22 \%)$ & $12(17 \%)$ & $1.41(1.19-1.66)$ \\
\hline Obese & $3812(29 \%)$ & $208(27 \%)$ & $4(13 \%)$ & $56(33 \%)$ & $29(33 \%)$ & $18(28 \%)$ & $0.87(0.74-1.03)$ \\
\hline$\geqslant 2 h$ PA per week & $5067(45 \%)$ & $248(35 \%)$ & $7(25 \%)$ & $59(37 \%)$ & $20(26 \%)$ & $25(40 \%)$ & $0.79(0.67-0.93)$ \\
\hline Current smoker & $4315(28 \%)$ & $197(21 \%)$ & $15(38 \%)$ & $48(23 \%)$ & $18(17 \%)$ & $14(20 \%)$ & $0.90(0.76-1.06)$ \\
\hline Former smoker & $5064(33 \%)$ & $400(43 \%)$ & $20(51 \%)$ & $84(41 \%)$ & $53(50 \%)$ & $38(54 \%)$ & $1.25(1.09-1.44)$ \\
\hline Alcohol > recommended & $2829(18 \%)$ & $151(16 \%)$ & $7(18 \%)$ & $23(11 \%)$ & $14(13 \%)$ & $13(18 \%)$ & $1.03(0.85-1.24)$ \\
\hline Former drinker & $1000(7 \%)$ & $79(9 \%)$ & $5(13 \%)$ & $12(6 \%)$ & $12(11 \%)$ & $7(9 \%)$ & $1.26(0.99-1.61)$ \\
\hline Numbers, percent and odds Ratios (OR) adjusted for age, sex and socio-economic deprivation. Scottish Health Survey participants aged >45 years (unweighted analysis). \\
\hline
\end{tabular}

Table 3. Health behaviours in cancer survivors and participants who subsequently developed cancer by recent ( $<2$ years) or less recent ( $\geqslant 2$ years) cancer diagnosis

\begin{tabular}{|c|c|c|c|c|c|c|c|}
\hline & \multicolumn{4}{|c|}{$\begin{array}{l}\text { Diagnosed before survey } \\
\qquad O R_{\mathrm{adj}}\end{array}$} & \multicolumn{3}{|c|}{$\begin{array}{l}\text { Diagnosed after survey } \\
\qquad \mathrm{OR}_{\mathrm{adj}}\end{array}$} \\
\hline & \multicolumn{2}{|c|}{$\geqslant 2$ years } & \multicolumn{2}{|c|}{$<2$ years } & \multicolumn{2}{|c|}{$<2$ years } & \multirow{2}{*}{$\begin{array}{c}\geqslant 2 \text { years } \\
n(\%)\end{array}$} \\
\hline & OR $(95 \% \mathrm{Cl})$ & $n(\%)$ & OR $(95 \% \mathrm{Cl})$ & $n(\%)$ & OR $(95 \% \mathrm{Cl})$ & $n(\%)$ & \\
\hline$\geqslant 5$-a-day & $2.40(1.80-3.20)^{\star}$ & $141(20.2)$ & $3.14(2.14-4.61)^{\star}$ & $52(23.3)$ & $1.23(0.78-1.96)$ & $26(10.8)$ & $91(9.0)$ \\
\hline Obese & $0.88(0.69-1.11)$ & $153(26.1)$ & $1.07(0.75-1.52)$ & $55(30.4)$ & $0.68(0.48-0.98)^{\star}$ & $46(21.8)$ & $258(28.5)$ \\
\hline$\geqslant 2 \mathrm{~h} \mathrm{PA} /$ per day & $1.14(0.89-1.46)$ & $200(36.7)$ & $0.74(0.51-1.09)$ & $48(28.4)$ & $1.18(0.82-1.70)$ & $66(38.2)$ & $218(35.6)$ \\
\hline Current smoker & $0.60(0.47-0.76)^{*}$ & $145(20.7)$ & $0.59(0.41-0.83)^{*}$ & $52(23.3)$ & $1.02(0.75-1.39)$ & $80(33.2)$ & $367(36.1)$ \\
\hline Former smoker & $1.40(1.14-1.72)^{*}$ & $308(44.1)$ & $1.30(0.96-1.77)$ & $92(41.3)$ & $1.05(0.78-1.42)$ & $88(36.5)$ & $333(32.8)$ \\
\hline Alcohol > recommended & $1.02(0.79-1.32)$ & $118(16.9)$ & $0.81(0.54-1.23)$ & $33(14.8)$ & $1.01(0.69-1.48)$ & $42(17.5)$ & $196(19.3)$ \\
\hline Former drinker & $1.34(0.91-1.97)$ & $53(7.6)$ & $2.07(1.27-3.38)^{\star}$ & $26(11.7)$ & $1.10(0.62-1.96)$ & $16(6.7)$ & $58(5.71)$ \\
\hline
\end{tabular}


such as survival (Fong et al, 2012). Further research is needed to confirm whether cancer outcomes are improved through other interventions, such as low-fat or high-fibre diets (Meyerhardt et al, 2007; Davies et al, 2011).

The strengths of our analysis include a relatively large and representative sample size, validated methodologies, the use of cancer registry data rather than self-reported cancer diagnosis (Williams et al, 2013) and differentiation between site-specific cancers. Its weaknesses include lack of validity of self-reported health behaviours. However, because Scottish Health Surveys are not carried out on any specific patient or risk group, we think it is less likely that there would be systematic over- or under-reporting of particular behaviours. We were unable to track behaviour change over time so we cannot say, from these cross-sectional data, whether the observed differences are a result of survivor bias or whether behaviours do change as a result of diagnosis, symptoms or treatment. Longitudinal prospective studies are needed to collect data on symptoms, treatment and behaviour change.

\section{AUTHOR CONTRIBUTIONS}

All authors contributed to the design of the study; ZW and DSM conducted analyses of data; all authors contributed to drafting the manuscript.

\section{CONFLICT OF INTEREST}

The authors declare no conflict of interest.

\section{REFERENCES}

Alfano CM, Day JM, Katz ML, Herndon 2nd JE, Bittoni MA, Oliveri JM, Donohue K, Paskett ED (2009) Exercise and dietary change after diagnosis and cancer-related symptoms in long-term survivors of breast cancer: CALGB 79804. Psycho-oncology 18(2): 128-133.

Anderson AS, Craigie AM, Caswell S, Treweek S, Stead M, Macleod M, Daly F, Belch J, Rodger J, Kirk A, Ludbrook A, Rauchhaus P, Norwood P, Thompson J, Wardle J, Steele RJC (2014) The impact of a bodyweight and physical activity intervention (BeWEL) initiated through a national colorectal cancer screening programme: randomised controlled trial. Br Med J 348: g1823.

Bassett JC, Gore JL, Chi AC, Kwan L, McCarthy W, Chamie K, Saigal CS (2012) Impact of a bladder cancer diagnosis on smoking behavior. J Clin Oncol 30(15): 1871-1878.

Bidstrup PE, Dalton SO, Christensen J, Tjonneland A, Larsen SB, Karlsen R, Brewster A, Bondy M, Johansen C (2013) Changes in body mass index and alcohol and tobacco consumption among breast cancer survivors and cancer-free women: A prospective study in the Danish Diet, Cancer and Health Cohort. Acta Oncol 52(2): 327-335.

Corbett J, Dobbie F, Doig M, D’Souza J, Given L, Gray L, Leyland A, MacGregor A, Marryat L, Maw T, Miller M, Mindell J, Ormston R, Roth M, Sharp C (2009) Scottish Health Survey 2009 - volume 2: technical report. National Statistics: Edinburgh.

Coups EJ, Ostroff JS (2005) A population-based estimate of the prevalence of behavioral risk factors among adult cancer survivors and noncancer controls. Prev Med 40(6): 702-711.

Courneya KS (2003) Exercise in cancer survivors: an overview of research. Med Sci Sports Exerc 35(11): 1846-1852.

Courneya KS, Katzmarzyk PT, Bacon E (2008) Physical activity and obesity in Canadian cancer survivors: population-based estimates from the 2005 Canadian Community Health Survey. Cancer 112(11): 2475-2482.

Davies NJ, Batehup L, Thomas R (2011) The role of diet and physical activity in breast, colorectal, and prostate cancer survivorship: a review of the literature. Br J Cancer 105(Suppl 1): S52-S73.
Demark-Wahnefried W, Aziz NM, Rowland JH, Pinto BM (2005) Riding the crest of the teachable moment: promoting long-term health after the diagnosis of cancer. J Clin Oncol 23(24): 5814-5830.

Demark-Wahnefried W, Pinto BM, Gritz ER (2006) Promoting health and physical function among cancer survivors: Potential for prevention and questions that remain. J Clin Oncol 24(32): 5125-5131.

Evangelista LS, Sarna L, Brecht ML, Padilla G, Chen J (2003) Health perceptions and risk behaviors of lung cancer survivors. Heart Lung 32(2): 131-139.

Fairley TL, Hawk H, Pierre S (2010) Health behaviors and quality of life of cancer survivors in Massachusetts, 2006: data use for comprehensive cancer control. Prev Chronic Dis 7(1): A09.

Fong DY, Ho JW, Hui BP, Lee AM, Macfarlane DJ, Leung SS, Cerin E, Chan WY, Leung IP, Lam SH, Taylor AJ, Cheng KK (2012) Physical activity for cancer survivors: meta-analysis of randomised controlled trials. BMJ 344: e70.

Hawkes AL, Chambers SK, Pakenham KI, Patrao TA, Baade PD, Lynch BM, Aitken JF, Meng X, Courneya KS (2013) Effects of a telephone-delivered multiple health behavior change intervention (CanChange) on health and behavioral outcomes in survivors of colorectal cancer: a randomized controlled trial. J Clin Oncol 31(18): 2313-2321.

Inoue-Choi M, Lazovich D, Prizment AE, Robien K (2013) Adherence to the World Cancer Research Fund/American Institute for cancer research recommendations for cancer prevention is associated with better healthrelated quality of life among elderly female cancer survivors. J Clin Oncol 31(14): 1758-1766.

Izano MA, Fung TT, Chiuve SS, Hu FB, Holmes MD (2013) Are diet quality scores after breast cancer diagnosis associated with improved breast cancer survival? Nutr Cancer 65(6): 820-826.

Kim RB, Phillips A, Herrick K, Helou M, Rafie C, Anscher MS, Mikkelsen RB, Ning Y (2013) Physical activity and sedentary behavior of cancer survivors and non-cancer individuals: results from a national survey. PLoS One 8(3): e57598.

Littman AJ, Tang MT, Rossing MA (2010) Longitudinal study of recreational physical activity in breast cancer survivors. J Cancer Survivorship-Res Pract 4(2): 119-127.

Mayer DK, Carlson J (2011) Smoking patterns in cancer survivors. Nicotine Tob Res 13(1): 34-40.

Mayer DK, Terrin NC, Menon U, Kreps GL, McCance K, Parsons SK, Mooney KH (2007) Health behaviors in cancer survivors. Oncol Nurs Forum 34(3): 643-651.

Meyerhardt JA, Niedzwiecki D, Hollis D, Saltz LB, Hu FB, Mayer RJ, Nelson H, Whittom R, Hantel A, Thomas J, Fuchs CS (2007) Association of dietary patterns with cancer recurrence and survival in patients with stage III colon cancer. JAMA 298(7): 754-764.

Midtgaard J, Christensen JF, Tolver A, Jones LW, Uth J, Rasmussen B, Tang L, Adamsen L, Rorth M (2013) Efficacy of multimodal exercise-based rehabilitation on physical activity, cardiorespiratory fitness, and patientreported outcomes in cancer survivors: a randomized, controlled trial. Ann Oncol 24(9): 2267-2273.

Rogers LQ, Courneya KS, Paragi-Gururaja R, Markwell SJ, Imeokparia R (2008) Lifestyle behaviors, obesity, and perceived health among men with and without a diagnosis of prostate cancer: A population-based, cross-sectional study. BMC Public Health 8: 23.

Scottish Index of Multiple Deprivation: Background and Methodology. The Scottish Government (2012) Available at http://www.scotland.gov.uk/ Topics/Statistics/SIMD/BackgroundMethodologyAccessed 20/3/14.

Sprague BL, Trentham-Dietz A, Nichols HB, Hampton JM, Newcomb PA (2010) Change in lifestyle behaviors and medication use after a diagnosis of ductal carcinoma in situ. Breast Cancer Res Treat 124(2): 487-495.

Williams K, Steptoe A, Wardle J (2013) Is a cancer diagnosis a trigger for health behaviour change? Findings from a prospective, population-based study. Br J Cancer 108(11): 2407-2412.

This work is published under the standard license to publish agreement. After 12 months the work will become freely available and the license terms will switch to a Creative Commons AttributionNonCommercial-Share Alike 3.0 Unported License. 